\title{
Reflexões sobre a trajetória percorrida por um projeto de Educação Ambiental em um colégio privado, Pitanga -PR: RELATO DE EXPERIÊNCIA
}

\section{RESUMO}

Marcos Freitas marcaofreitasip@hotmail.com 0000-0003-1252-1375

Universidade Estadual do Centro Oeste, Guarapuava, Paraná, Brasil.

\section{Adriana Massaê Kataoka} dri.kataoka@hotmail.com 000-0001-8603-958 do Centro Oeste Guarapuava, Paraná, Brasil.

\section{Ana Lucia Suraini Affonso} analuciabio@gmail.com

Universidade Estadual do Centro Oeste. Guarapuava, Paraná, Brasil.

Marcos Paulo Trindade da Veiga marcosptv@gmail.com

Universidade Estadual do Centro Oeste, Guarapuava, Paraná, Brasil.

Elizabete França

elizabete87@hotmail.com

0000-0002-0690-4962

Universidade Estadual do Centro Oeste,

Guarapuava, Paraná, Brasil.
Este artigo teve como objetivo relatar a experiência de um projeto que abordou a temática ambiental em uma escola privada de Pitanga-PR, durante o ano de 2014, envolvendo todo o corpo docente. São descritas as discussões junto à equipe pedagógica e professores, além das atividades realizadas pelos mesmos. As ações promovidas pelos professores foram disponibilizadas em um site educacional, contribuindo com a sistematização, socialização e reflexão sobre as ações. Observou-se o envolvimento de professores de diferentes áreas e avaliou-se a efetividade dessa participação em torno da temática ambiental e o comprometimento demonstrado ao longo do processo. Verificou-se também que muitas ações ainda ocorreram pontualmente, eventualmente carecendo de criticidade. Considerando que a educação é um processo contínuo e que existe uma carência de conteúdo ambiental na formação dos professores, consideramos o envolvimento dos mesmos um grande avanço. Embora a pesquisa tenha durado um ano, as ações ainda continuam na escola, que podem evoluir no sentido de ampliar a criticidade dos envolvidos.

PALAVRAS-CHAVE: Meio Ambiente; Tecnologias de Informação e Comunicação; Educação Socioambiental. 


\section{INTRODUÇÃO}

O presente artigo relata a experiência do desenvolvimento de um projeto cujo título foi "Escolas Sustentáveis" aplicado em uma escola particular do munícipio de Pitanga - PR. O referido colégio realiza tradicionalmente um projeto temático durante o ano letivo. No ano de 2014 o tema escolhido teve por objetivo agregar a escola como um todo em torno da temática ambiental. É importante esclarecer que o primeiro autor desse trabalho também é o diretor da escola e que, além disso, cursa um Programa de Mestrado em Ensino de Ciências e Matemática, desenvolvendo uma proposta de dissertação em torno da temática ambiental. Todos esses interesses potencializaram a realização do projeto acima mencionado.

O projeto envolvendo a temática ambiental na referida escola nasceu, portanto de uma intencionalidade do autor que transcende a sua necessidade de realizar uma pesquisa de mestrado, mas se sustenta especialmente na sua vivência no cotidiano da escola em questão. $O$ interesse do autor relacionado à inserção da temática ambiental na escola de maneira mais efetiva se deu a partir de suas observações empíricas de iniciativas pontuais relacionadas à temática ambiental que ocorriam por parte de professores de ciências, e biologia no referido colégio, antes do início do projeto. Ou seja, a maioria dos professores que possuíam outra formação não se envolvia, contrariamente ao que se postula na Política Nacional de Educação Ambiental.

Essas preocupações culminaram na proposta do projeto, o qual possuía como objetivo primeiro, provocar uma ampla reflexão, envolvendo a escola como um todo em torno da temática ambiental. $\mathrm{O}$ fato do autor da pesquisa e, portanto da proposta do projeto ser o diretor da escola trouxe algumas facilidades e algumas dificuldades.

Assim, o presente artigo tem por objetivo relatar e ao mesmo tempo refletir sobre as etapas percorridas pelo processo de inserção da Educação Ambiental (EA) no colégio, dificuldades encontradas, soluções construídas e ações realizadas durante ano de 2014. Também objetivou avaliar as atividades realizadas pelos professores.

Dessa forma, o desafio proposto pelo projeto foi de inserir a EA de forma participativa no contexto escolar, de modo que os professores tivessem autonomia para conduzir as atividades da forma que considerassem mais apropriada, respeitando os limites de cada um, e ao mesmo tempo estimulando a inciativa, a criatividade, a autonomia, o diálogo e a reflexão.

Sendo assim, neste artigo iniciamos com uma breve reflexão sobre a EA no contexto escolar a partir do referido projeto, em seguida descrevemos o percurso metodológico, para finalmente relatar a experiência a qual foi organizado em 5 momentos pedagógicos a saber:

1 - Apresentação da proposta à equipe pedagógica e professores.

2 - Diagnóstico de alunos professores e pais sobre suas concepções de ambiente

3 - Problematização da temática e formação para os professores

4 - Desenvolvimento de atividades

5 - Construção de um site educacional. 


\section{CONSIDERAÇÕES SOBRE A EA NO ÂMBITO ESCOLAR}

A EA surge em um contexto de crise, a partir do momento que problemas ambientais começam a ser denunciados pelos movimentos sociais nas décadas 1960 e 70 . A sociedade da época começava a temer a contaminação causada por diferentes fontes colocando em risco a sua saúde do ambiente (CARVALHO, 2004).

Durante a conferência de Estocolmo em 1972, a EA foi apontada como uma solução para buscar respostas aos problemas que estavam surgindo e que precisavam de uma solução pensada de forma conjunta. Sendo nesse momento, estabelecidos os princípios regentes da EA. Princípios esses, complementados com a realização da Conferência em Tbilisi em 1977, onde foi postulado que a EA tem como objetivo buscar a resolução dos problemas de forma coletiva, sendo essencial a participação dos diversos setores da sociedade em uma discussão ampla sobre as problemáticas ambientais, suas causas e consequências.

Maia (2015) afirma que a EA se constitui como uma das mais importantes alternativas para enfrentar os impactos da ação humana nos ecossistemas e em suas interações sociais. É importante considerar que EA é um campo do conhecimento que envolve várias áreas do saber e, portanto, possui um caráter polissêmico, mas de maneira geral pressupõe ações que modifiquem os valores e a conduta dos atores sociais envolvidos (MAIA, 2015).

Sauvé (2005), em um esforço para a apreensão de diversas possibilidades teóricas e práticas no campo da EA elaborou um mapa deste "território" pedagógico identificando 15 correntes de EA, estas foram agrupadas de forma a relacionar pontos comuns, oposição, divergências e complementariedades. A autora também divide as correntes entre as de longa tradição e as mais recentes. Layrargues (2003), também destaca a existência e uma ampla variedade de vertentes de EA, que se inserem em um gradiente, buscando uma mudança ambiental conquistada pelo intermédio de três possibilidades: a mudança cultural associada à estabilidade social; a mudança social associada à estabilidade cultural; e finalmente, a mudança cultural concomitante á mudança social. $\mathrm{O}$ autor ainda alerta para a dificuldade de identificar as intencionalidades que preenchem de sentido as ações de EA.

Entre as concepções de EA ditas de longa tradição, ou conservadoras segundo Guimarães (2007), encontram-se aquelas que enfatizam a dimensão ecológica do ambiente, e práticas moralistas como se os problemas ambientais fossem originados independentes das práticas sociais. E entre as mais recentes encontram-se aquelas denominadas de críticas ou ainda crítica e emancipatória.

A abordagem de EA crítica e emancipatória nutre-se das pedagogias progressistas histórico-crítica e libertária, que são correntes voltadas para a transformação social, e tal abordagem considera essencial uma contextualização histórica e social (LOUREIRO, 2012).

A prática da EA na Educação Formal encontra apoio legal desde 1999 na meio ambiente como tema transversal. Mais recentemente, foi promulgada a 
Diretriz Curricular da Educação Ambiental de 2012 a qual avança no sentido de enfatizar a importância de uma EA crítica.

No âmbito do estado do Paraná, em janeiro de 2014, a EA foi incorporada aos conteúdos curriculares e na gestão escolar das redes pública e particular de ensino em consonância, com a Lei 17.505/2013, aprovada pelo Conselho Estadual de Educação e sancionada pelo governador Carlos Alberto Richa. Essa foi a última etapa para a implementação da Política Estadual de Educação Ambiental e o Sistema Estadual de Educação Ambiental no Paraná.

Embora haja esse amparo legal para a implementação da EA formal, muitos trabalhos vem relatando dificuldades com a inserção da EA no âmbito escolar. Guimarães (2007), relata que mesmo com as dificuldades encontradas para trabalhar a EA, ela está implantada no dia a dia das escolas, graças a movimentos espontâneos de educadores que estão preocupados com a crise socioambiental. Apesar da boa vontade desses professores, ainda é realizada nas escolas uma E A conservacionista que passivamente reproduz as atividades que já vêm sendo realizadas no decorrer dos anos sem avanços significativos.

Outro aspecto que tem sido intensamente debatido possui implicações diretas na inserção da EA no contexto escolar, diz respeito a formação de professores. Maia (2015) menciona deficiência na formação profissional dos professores, no que se refere à EA, como uma das dificuldades para a inserção na sua prática pedagógica. Sobre essa deficiência na formação dos professores, alguns autores têm apresentado propostas que atendam aos princípios da EA. Medina (2000) destaca que quando se trata de Cursos de Formação em Educação Ambiental, é fundamental que os professores vivam no próprio curso uma experiência de $E A$, o que implica propiciar-lhes os instrumentos necessários para serem os agentes da própria formação.

Quando se trata da temática ambiental na escola, na maioria das vezes, o entendimento da escola é que professores da área de biologia e geografia são os mais qualificados para trabalhar o tema (TRAVASSOS, 2004). Essa situação pode ser justificada pelo fato da EA ter surgido em um terreno marcado por uma tradição naturalista, e consequentemente, influenciada por essa área do conhecimento (CARVALHO, 2004).

Por outro lado, a pesquisa de Araújo e Oliveira (2008), afirma que a maioria dos docentes Biologia e EA, no que diz respeito ao meio ambiente, que em sua formação inicial receberam apenas informações sobre ecologia em disciplinas desconectadas. Essa formação deficiente leva a resultados como encontrados por Freire et al. (2006), que relatam que muitos trabalhos ditos de EA restringem-se a conteúdos ecológicos, voltados somente para conservação da natureza, sem fazer referência a dimensão econômica e social.

\section{PERCURSO METODOLÓGICO}

A presente investigação adotou os preceitos da abordagem qualitativa, a qual se preocupa com um nível de realidade que não pode ser quantificado (MINAYO, 2003; FLICK, 2004). 
O principal instrumento utilizado foi a observação participante onde o diretor atuou como observador participante durante todo o trabalho e registrou todo o processo em um "diário de bordo". Gil (1995) explica que a observação participante, ou observação ativa, consiste na participação real na vida da comunidade, do grupo ou de uma situação determinada. Nesse caso, o observador assume, pelo menos a certo ponto, o papel de um membro do grupo. Daí por que se pode definir observação participante como a técnica pela qual se chega ao conhecimento da vida de um grupo a partir do seu interior.

A análise de conteúdo descrita por Bardin (1977) foi utilizada para avaliar a descrição das atividades realizadas pelos professores. Para a autora a análise de conteúdo, enquanto método torna-se um conjunto de técnicas de análise das comunicações que utiliza procedimentos sistemáticos e objetivos de descrição do conteúdo das mensagens. A descrição das atividades foi transcrita por cada professor que participou do projeto, eles preencheram uma ficha que versava sobre objetivo, descrição da atividade, resultados, além de aspectos positivos e negativos.

O trabalho foi desenvolvido em uma escola privada do Município de PitangaPR que contempla a Educação Infantil (maternal a pré-escola), Ensino Fundamental I ( $1^{\circ}$ a $5^{\circ}$ série), Fundamental II ( $6^{\circ}$ a $9^{\circ}$ série) e Ensino Médio.

\section{Apresentação da proposta}

O colégio João Paulo II tem como política, realizar anualmente um projeto que aborda um tema específico, este projeto é desenvolvido durante o ano letivo por toda a comunidade escolar. Os professores possuem autonomia para criar propostas individualizadas relacionadas ao tema em sua disciplina ou realizar atividades junto com outros professores. Alguns momentos específicos, como datas comemorativas, são utilizados para enfatizar o projeto e os esforços conjuntos.

Aproveitando essa prática já consolidada no colégio e o fato do pesquisador ser o diretor da escola, no ano de 2014 foi proposto o tema "Escolas Sustentáveis", a fim de iniciar a inserção da temática ambiental no colégio a partir dos princípios da EA. Ainda foi incluída na proposta a criação de um site educacional. Foi possível desta forma, aliar a pesquisa do mestrado profissional do primeiro autor do trabalho com sua prática profissional no colégio. Uma das exigências do mestrado profissional é desenvolver um produto que possa de alguma forma ser replicado para outras experiências similares e que tenha aplicabilidade no ensino. Desta forma, foi agregada a proposta do tema "Escolas Sustentáveis", a produção de material educativo voltado para a temática em questão, o qual foi disponibilizado em ambiente virtual. A escolha do site como produto, se deu em função da possibilidade de propiciar o registro e socialização das experiências que seriam realizadas, de propiciar um canal de diálogo e interação entre a comunidade escolar e comunidade do entorno e de se configurar em uma ferramenta atrativa aos jovens.

A proposta foi apresentada à equipe pedagógica do colégio em janeiro de 
preocupação em atender a legislação, no caso a Política Nacional de Educação (1999) e a Diretriz Curricular de Educação Ambiental (2012), que recomendam, entre outras coisas, que a EA seja prática em todos os níveis de ensino. Alguns membros da equipe demonstraram certa preocupação relacionada a aceitabilidade entre os professores, já que alguns não percebem uma relação direta entre o tema e sua disciplina, outros ainda poderiam ter uma preocupação com o andamento de seu conteúdo, preocupação essa que costuma ser levantada nesses momentos.

No mês seguinte, a proposta foi a presentada aos professores e funcionários na reunião pedagógica. Foi nítida e compreensível a preocupação apresentada por alguns professores. Por outro lado, muitos ressaltaram a importância em se trabalhar temas como esse, destacando que já é de domínio público a dimensão da gravidade dos problemas ambientais na atualidade. Na sequência professores e funcionários foram agrupados por níveis de ensino que atuam, para elencar algumas propostas a serem trabalhadas com os alunos já no início do ano letivo. No final foi feita uma plenária com as propostas, neste momento a apreensão percebida no início da reunião foi substituída pelo entusiasmo demonstrado pela maioria de professores e pelos funcionários ao apresentarem suas propostas.

No período de fevereiro a março a proposta foi apresentada gradativamente ao colégio como um todo. Percebia-se nesse momento que alguns professores estavam relutantes em iniciar suas ações. Em conversas informais, estes relatavam uma insegurança relacionada ao fato de não terem tido formação na área.

\section{Diagnóstico}

Esse momento da pesquisa foi importante para se conhecer como os atores da escola concebem meio ambiente e EA. Segundo alguns autores cada concepção possui uma implicação na relação que se tem com o ambiente. Esse momento consistiu na aplicação de questionário semiaberto a professores e funcionários.

Com os alunos foi realizada apenas uma pergunta, a saber: 0 que você entende por meio ambiente. A diferença é que estes foram orientados a utilizarem 3 formas diferenciadas de expressão, escrita, foto e desenho. Essa atividade, além de nos proporcionar o conhecimento sobre a concepção desses alunos sobre meio ambiente, também se configurou em um momento de reflexão e contato com seu ambiente imediato intermediado pelo uso de uma tecnologia (câmeras fotográficas de celular) focalizando aspectos do ambiente.

Essa investigação não é foco desse artigo, que se propôs a relatar o processo como um todo. Mas de maneira geral, prevaleceu para todos os grupos uma concepção naturalista de ambiente. Essa informação foi fundamental para subsidiar a continuidade do projeto, principalmente sobre a decisão em se realizar momentos formativos com os professores.

\section{Problematização da temática e formação}

Essa etapa do projeto se deu em função dos resultados apresentados pelo diagnóstico, conforme já mencionado e observações relacionadas a insegurança apresentada por uma parte dos professores em dar início as atividades. 
As concepções de meio ambiente apresentadas por alunos, pais, professores e funcionários também revelaram a necessidade de um momento de formação, já que a concepção que prevaleceu foi a naturalística, considerada por muitos autores como ingênua, idealizada e que muito pouco contribui com para a reflexão em torno das causas e soluções da problemática ambiental (REIGOTA, 2010; SAUVÉ, 2005).

A partir dessas constatações foram organizados dois momentos, os quais chamamos de problematização da temática e formação. O primeiro momento (problematização) ocorreu logo no início do ano letivo com uma palestra proferida por um representante da Secretaria do Meio Ambiente do município de Pitanga para alunos e professores, o qual fez uma fala a respeito do tema e o lançamento do projeto da escola. O representante também aproveitou a oportunidade para relatar o trabalho que a Secretaria do Meio Ambiente vem realizando com o cuidado das nascentes de água do município de Pitanga. Esse relato permitiu aos participantes perceber que é possível sair da teoria à prática, estimulando assim o início do projeto na escola, minimizando as inseguranças.

O segundo momento (formação) aconteceu em julho na semana pedagógica, - qual se deu em função da observação que alguns professores ainda apresentavam dúvidas e incertezas em relação ao tema de sustentabilidade, meio ambiente e EA e em relação a como trabalhar no seu cotidiano. Nesse momento foram convidadas professoras do departamento de Ciências Biológicas da UNICENTRO, atuantes no campo da EA e docentes do Mestrado em Ensino de Ciências e Matemática. As professoras fizeram uma reflexão sobre o surgimento da EA, seus conceitos e objetivos, também falaram sobre as diferentes concepções de Ambiente e suas implicações na relação sociedade ambiente, destacando que a concepção aceita pela EA é a socioambiental. Segundo relatos dos próprios professores, "foi um momento maravilhoso de capacitação". Depois da fala das professoras, foi perceptível um envolvimento maior dos professores no projeto, pois falavam frequentemente sobre a necessidade da sensibilização e em como tornar a escola sustentável. Nesse momento houve um envolvimento maior até mesmo daqueles professores que não tinham se envolvido diretamente com o projeto, estes passaram a ter uma preocupação com o que deveria ser feito na escola para que os pais percebessem a importância da questão ambiental. Ou seja, não somente passaram a se envolver de fato, como também se preocupavam com o envolvimento de outros.

\section{Desenvolvimento de Atividades}

As ações realizadas pelos professores tiveram início entre os meses de março e abril. A tabela 1 retrata quais foram os professores que participaram por disciplina e por série. A tabela 1 revela uma ampla adesão dos professores ao projeto. Vale ressaltar que essa situação pode ser explicada em função do pesquisador ser o diretor do colégio e, além disso, se tratar de um colégio particular, essa condição nos proporcionou essa vantagem, mas por outro lado as adesões podem não ter ocorrido de forma tão espontânea. Entretanto, a escola já possuía uma tradição de realizar um projeto temático a cada ano, e a ampla adesão talvez tenha sido algo natural para os professores. 
De qualquer forma, acreditamos que essa condição não compromete os resultados do trabalho, já que existe uma legislação que fala da obrigatoriedade da inserção da EA nos currículos, e um diretor consciente dessa necessidade pode potencializar o seu cumprimento.

Tabela 1: Determinação das disciplinas e da quantidade de professores envolvidas no projeto "Escolas Sustentáveis" por nível de ensino.

Níveis de Ensino

\begin{tabular}{|c|c|c|c|}
\hline Disciplinas & Ed. Infantil & Ens. Fund. & Ens. Médio \\
\hline Matemática & & 1 & 1 \\
\hline Português & & 1 & \\
\hline Literatura & & & 1 \\
\hline Inglês & & 1 & \\
\hline Espanhol & & 1 & 1 \\
\hline Artes & & 1 & \\
\hline Física & & 1 & 1 \\
\hline Geografia & & 1 & 1 \\
\hline Ciências & & 2 & \\
\hline Biologia & & & 1 \\
\hline História & & 1 & 1 \\
\hline Ed. Física & & 1 & \\
\hline Química & & & 1 \\
\hline Filo./Sociol. & & & 1 \\
\hline Total & 8 & 16 & 9 \\
\hline
\end{tabular}

Obs: Em virtude de haver apenas um professor por turma na Educação Infantil, os mesmos apenas foram totalizados ao final da tabela. O número total de professores é diferente do total de professores envolvidos no projeto por que alguns ministram mais de uma disciplina e alguns não se identificaram.

Fonte: Elaborado pelos autores

Envolveram-se com o projeto professores de educação infantil, ensino fundamental e ensino médio (Tab. 1). Vale destacar que não somente professores de ciências e biologia realizaram atividades, mas professores de praticamente todas as disciplinas. Esse fato contraria o que tradicionalmente tem sido descrito na literatura, como relatado por Travassos (2004), que aponta que a maioria das ações que envolvem a temática ambiental são realizadas por professores de biologia e geografia. Por outro lado, esses resultados se aproximam das recomendações dos documentos oficiais da EA que instruem que a temática seja trabalhada de maneira transversal, ou seja, por todas as disciplinas. 
Figura 1. Relação entre o número de alunos e a suas concepções de Educação Ambiental determinados na fase de diagnóstico do projeto. Categorias de concepções de Educação Ambiental foram determinadas segundo Sauvé (2005).

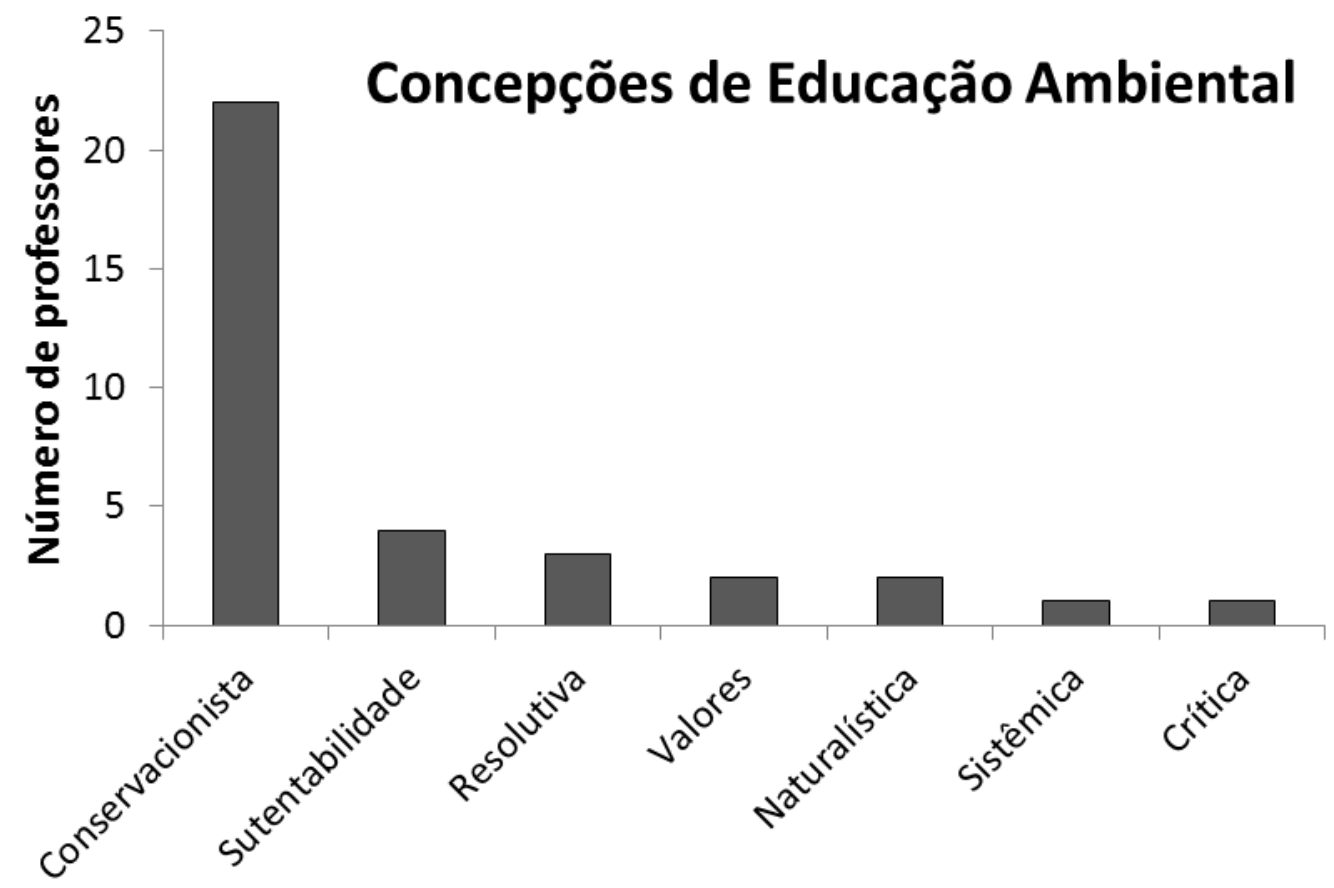

Fonte: Elaborado pelos autores

A partir dos registros que os professores fizeram sobre a realização de suas atividades, procedemos a análise para identificar qual concepção de EA estava implícita em sua prática, de acordo com as categorias propostas por Sauvé (2005). A figura 1 ilustra os resultados alcançados.

Foi marcante a criatividade apresentada pelos professores em realizar e relacionar atividades com a sua disciplina. Apesar do tema central ser sustentabilidade, foi proposta uma grande diversidade de abordagens de EA (Fig. 1). Com as crianças da educação infantil foram predominantes atividades realizadas com materiais recicláveis, criando brinquedos e trabalhando-se o lúdico. Foram classificados como EA conservacionista todos os trabalhos relacionados com confecção de brinquedos a partir de resíduos recicláveis, por considerar que essas atividades visavam promover uma reflexão sobre os resíduos e os problemas decorrente de sua destinação, portanto ligado ao conceito de gestão ambiental que se encontra diretamente relacionado a uma concepção de ambiente como recurso. Quanto ao enfoque lúdico Malaquias et al. (2012) afirmam que o elemento lúdico permite a cada pessoa se sentir cada vez mais segura para expor suas dúvidas e curiosidades, podendo aprender pelas descobertas das experiências vividas, a diversidade cultural a qual vive. Os autores ainda destacam que os jogos ambientais integram o lúdico e o conteúdo, auxiliando na educação formal e não formal, além de despertar a necessidade de conhecer, preservar e conservar o ambiente. 
Atividades relacionadas à concepção naturalística de ambiente foram pouco exploradas, se restringindo ao professor de biologia e a alguns professores do ensino fundamental.

Sobre o método de trabalho, a maioria se restringiu as suas disciplinas, e quanto a interdisciplinaridade na maioria dos casos se restringiu a sua disciplina em relação a algum aspecto que evocasse o ambiente. Essa dificuldade apresenta pelos professores pode ser justificada em função da própria estrutura curricular que é compartimentalizada em disciplinas e que, portanto dificulta um trabalho interdisciplinar. Carvalho (2004) discute que "a interdisciplinaridade jamais será uma posição fácil, cômoda ou estável" ela explica que se trata de um combate interno e externo e que exige nos desfazer dos condicionamentos históricos que nos constituem.

Por outro lado, alguns trabalhos envolveram a reflexão em relação ao contexto em que a escola se insere, ou seja, a comunidade. Este resultado indica um avanço em relação à maioria das abordagens, as quais se voltaram para ações pontuais e descontextualizadas, que segundo Loureiro (2012), reforçam a dicotomia humanidade-mundo.

De qualquer forma, foram observados avanços significativos no que diz respeito à inserção da temática ambiental na escola. Por outro lado, é inegável que existe ainda um longo caminho a ser trilhado, caminho este que não diz respeito apenas às questões ambientais, mas que faz parte de um complexo quadro de dificuldades, pelo qual tem passado a educação brasileira. Maia (2015) chama a atenção para fato de que a profissionalização do professor passa por um processo de internacionalização do capital, globalização e descaracterização cultural, os quais levam o professor à adoção de concepções prático-utilitária, fundadas numa racionalidade técnica as quais comprometem uma reflexão crítica.

\section{Criação do Site}

A criação do site teve por objetivo subsidiar as ações dos professores e alunos a partir de textos que fundamentam a prática educativa sob a perspectiva da EA. Bem como, a postagem das ações pôde socializar as atividades realizadas no projeto com toda comunidade escolar. A utilização dos avanços tecnológicos pode ser um elemento facilitador das nossas atividades, o domínio das novas ferramentas nos permite ampliar a disseminação de informações de forma prática e rápida. Com um conteúdo dinâmico e atual, a EA pode e deve se valer das facilidades que as Tecnologias da Informação e Comunicação (TICs) trazem, usando-as como instrumentos para ampliar a penetração de seus conteúdos e concepções (MORAN, 2000). Buscando o uso das TICs, este projeto se propôs a criar um site educacional com conteúdos de EA.

A estruturação dos conteúdos esta apresentada de forma hierarquizada (Fig. 2). As diferentes ações promovidas pelos professores foram inseridas nas respectivas categorias. Sendo uma metodologia dinâmica, o mapa está sujeito a variações ao longo do tempo. 


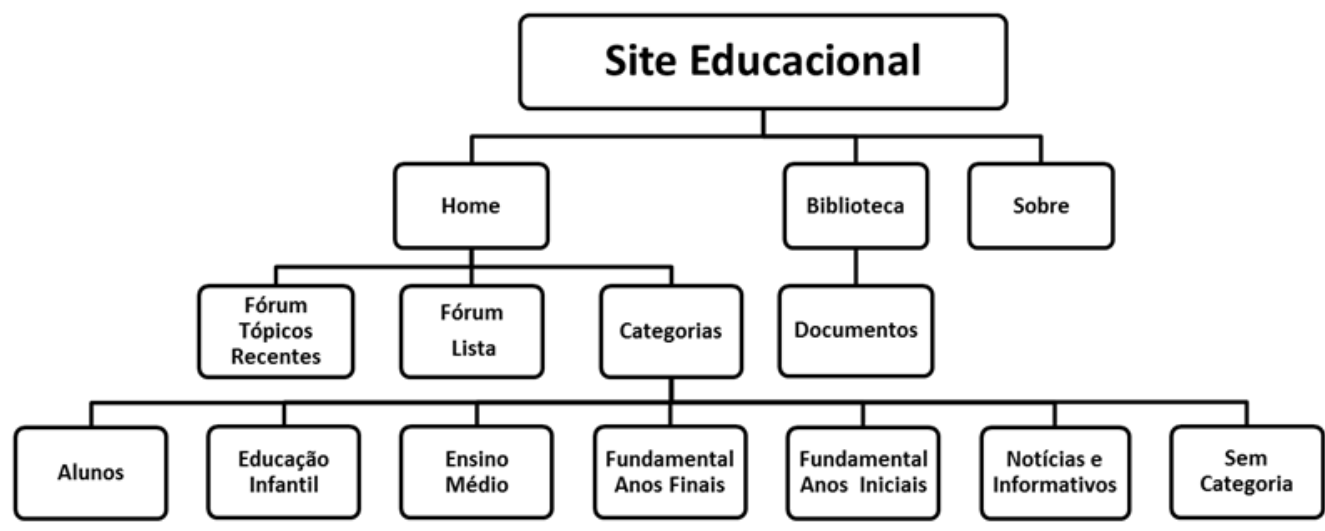

Fonte: Elaborado pelos autores

Desta forma o site cumpriu com o papel de subsidiar as ações, principalmente dos professores, ao disponibilizar no item biblioteca documentos legais que fundamentam a EA no Brasil, como a Política Nacional de Educação Ambiental de 1999, a Diretriz Curricular Nacional de Educação Ambiental de 2012, Política Estadual de Educação Ambiental de 2013 e textos de autores renomados da EA.

Os espaços de socialização das atividades são amplos no site e foram divididos em Educação Infantil, Fundamental anos iniciais e finais e Ensino Médio. Os professores postaram suas ações, algumas dessas apontadas na Figura 1. Cabe destacar que nem todos os professores postaram as suas ações no site, esse dado pode estar associado a falta de familiaridade de alguns professores com as TICS.

Outro espaço que o site disponibiliza é o Fórum, este espaço foi destinado a postagem de algum assunto considerado relevante voltado para uma ampla discussão.

O site também tem um espaço destinado aos alunos, para que estes também possam se expressar e trazer assuntos para a reflexão.

Uma consulta realizada com todos os grupos, professores, funcionários, alunos e pais revelou que o site é acessado por todos, demonstrando que a socialização da temática está acontecendo e transcendendo os limites da escola.

\section{CONSIDERAÇÕES FINAIS}


Consideramos que o desafio proposto de inserir a temática ambiental no contexto escolar de maneira participativa envolvendo toda a escola foi atingido. Tanto a educação infantil, quanto ensino fundamental e o ensino médio tiveram professores e alunos envolvidos. Vale destacar que não somente professores de ciências e biologia realizaram atividades, mas professores de praticamente todas as disciplinas. Esse fato contraria o que tradicionalmente tem sido descrito na literatura ao mesmo tempo em que se aproxima das recomendações dos documentos oficiais da EA, os quais instruem que a temática seja trabalhada de maneira transversal. Atribuímos essa grande adesão ao fato do pesquisador ser o diretor da escola, mas não somente isso, mas também a tradição que a escola possui em desenvolver um tema de trabalho a cada ano letivo.

Embora tenha havido uma ampla adesão, alguns resultados apontaram para a adoção de abordagens pontuais e até certo ponto conservadoras, carecendo de criticidade. Em algumas situações houve esforços para uma contextualização da temática, pelo menos no que se refere ao contexto da realidade local, pecando ainda por uma contextualização histórica.

As cinco etapas pedagógicas em que o projeto foi organizado promoveram uma construção participativa e a continuidade das ações. A etapa do diagnóstico foi essencial para nos aproximarmos das concepções adotadas pelos professores, alunos e funcionários, e definiram a necessidade de momentos voltados para reflexão e formação coletiva.

Por outro lado, avaliamos que apenas dois momentos de formação foram insuficientes para dirimir as dúvidas dos professores, as quais foram reveladas em suas práticas conforme já mencionado. As dificuldades dos professores podem revelar um problema na sua formação inicial, disciplinar, fragmentada e que de alguma forma se encontra enraizada nos mesmos. Entendemos que a única alternativa é investir de forma mais intensa na formação continuada desses professores. Ao mesmo tempo em que identificamos essas fragilidades do projeto consideramos que o período de um ano é muito curto para promover os avanços propostos pela EA, mas ao entender que a educação é um processo contínuo e que o projeto apenas deu início ao processo, assim, acreditamos foram percorridos alguns passos na direção de uma EA voltada para a transformação da relação sociedade natureza.

A construção do site educacional materializou a divulgação de todas as ações, além de propiciar uma ampla socialização entre todos os envolvidos, adicionalmente, é importante destacar que o site continua ativo e configura-se em uma memória do projeto.

Acreditamos que o projeto deva ter continuidade e após um ano de experiência algumas possibilidades são vislumbradas com maior clareza. Investimentos na formação continuada dos professores fazem-se essenciais. Essa formação poderá ter o site como uma ferramenta importante, se adequando a disponibilidade de tempo dos professores a partir de ferramentas específicas agregadas ao mesmo. 


\title{
Reflections on the trajectory covered by an Environmental Education project in a private school, Pitanga -PR: EXPERIENCE REPORT
}

\begin{abstract}
This article aimed to the report of a experience of a project that addressed the environmental issue in a private school in Pitanga-PR, during the year 2014, involving the entire faculty. Discussions are described with the pedagogical team and teachers, as well as the activities carried out by them. The actions promoted by the teachers were made available on an educational website, contributing to the systematization, socialization and reflection on the actions. It was observed the involvement of teachers from different areas and the effectiveness of this participation around the environmental theme and the commitment demonstrated throughout the process. It was also verified that many actions still occurred punctually, possibly lacking in criticality. Taking into account that education is an continuous process and that there is a lack of environmental content in teacher training, we consider the involvement of teachers to be a major step forward. Although the research lasted a year, the actions still remain in school, which can evolve in order to increase the criticality of those involved..
\end{abstract}

KEYWORDS: Environmental. Information and Communication Technologies. Socio environmental education. 


\section{NOTAS}

\section{REFERÊNCIAS}

ARAÚJO, M. L. F.; OLIVEIRA, M. M. Formação de professores de biologia e educação ambiental: contribuições deficiências e estratégias. Revista Eletrônica do Mestrado em Educação Ambiental, v. 20, p. 256-273, jan./jul. 2008.

BARDIN, L. Análise de conteúdo. São Paulo: Edições 70, 1977.

CARVALHO, I. C. M. Educação Ambiental: a formação do sujeito ecológico. São Paulo: Cortez, 2004.

FLICK, U. Uma Introdução à Pesquisa Qualitativa. Porto Alegre: Bookman, 2004.

FREIRE, J. T.; NASCIMENTO, M. F. F.; SILVA, S. A. H. Diretrizes Curriculares de Educação Ambiental: as escolas da Rede Municipal de Ensino de Salvador. Salvador: SMEC. 164p. 2006.

GIL, A. C. Métodos e Técnicas de Pesquisas Sociais. 4 ed. São Paulo: Ed. Atlas S.A., 1995.

GUIMARÃES, M. A formação de educadores ambientais. 3 ed. Campinas: Ed. Papirus, 2007.

LAYRARGUES, P. P (org). Identidades da Educação Ambiental Brasileira / Ministério do Meio Ambiente. - Brasília: Ministério do Meio Ambiente, 2004.

LOUREIRO, C. F. B. Trajetória e Fundamentos da Educação Ambiental. 4 ed, São Paulo: Cortez, 2012.

MAIA, J. S. S. Educação Ambiental Crítica e Formação de professores. Curitiba: Ed. Appris Ltda, 2015.

MALAQUIAS, J. F.; et al. O Lúdico como promoção do aprendizado através dos jogos socioambientais, integrando educação formal e não formal. Revista Eletrônica do Mestrado em Educação Ambiental, v. 29,p. 1-16 jul/dez 2012.

MEDINA, N. M. A formação dos professores em Educação Fundamental. In: 
MINAYO, M. C. S. Ciência tecnologia e arte: o desafio da pesquisa social. In: (Org). Pesquisa social: teoria, método e criatividade. 22 ed. Petrópolis: Ed. Vozes, 2003.

MORAN, J. M.; et al. Novas tecnologias e mediação pedagógica. 6 ed. Campinas: Papirus, 2000.

REIGOTA, M. Meio ambiente e representações sociais. 8 ed. São Paulo: Cortez, 2010.

SAUVÉ, L. Uma cartografia das correntes em educação ambiental. In: SATO, M., CARVALHO, I. (Orgs.). Educação Ambiental: pesquisa e desafios. Porto Alegre: Artmed. p. 17-44. 2005.

TRAVASSOS, E. G. A prática da educação ambiental nas escolas. Porto Alegre: Mediação, 2004.

Recebido: 2016-06-28

Aprovado: 2017-06-04

DOI: $10.3895 /$ rbect.v10n2.4375

Como citar: FREITAS, M.; KATAOKA, A. M.; AFFONSO, A. L. S.; VEIGA, M. P. T. DA; FRANÇA, E.

Reflexões sobre a trajetória percorrida por um projeto de Educação Ambiental em um colégio privado,

Pitanga -PR: RELATO DE EXPERIÊNCIA. Revista Brasileira de Ensino de Ciência e Tecnologia, v. 10, n. 2, 2017. Disponível em: <https://revistas.utfpr.edu.br/rbect/article/view/4375>. Acesso em: xxx.

\section{Correspondência:}

Direito autoral: Este artigo está licenciado sob os termos da Licença Creative Commons-Atribuição 4.0 Internacional.

\section{(c) (1)}

